\title{
NOTAS SOBRE EL BIENESTAR
}

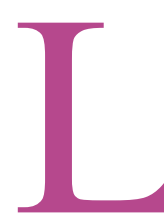

os trabajos precedentes constituyeron el objeto de discusión de las Jornadas celebradas en Tossa de Mar en abril de 1990. Jorge Malem, impulsor tenaz y alma, de esta cita anual, ha tenido la gentileza y, al propio tiempo, la poca perspicacia de encargar su comentario a un modesto profesor de filosofía del Derecho, que es más jurista que filósofo y que, en esto último, conoce poco y acaso mal la tradición cultural en que se inscriben algunas de las anteriores reflexiones. Sirva esta explicación para disculpar las muchas lagunas de mis observaciones, incapaces de compartir cierto lenguaje o de precisar el alcance de los ingeniosos ejemplos a que nos tiene acostumbrados cierta literatura. En consecuencia, me limitaré a exponer algunas ocurrencias nacidas de la lectura de las más doctas opiniones que el lector ya conoce.

Con todo, y como algo bueno siempre se contagia, aquí también comenzaremos con un ejemplo relativo al bienestar, aunque tenga su origen en fuentes distintas, concretamente en un texto de G. Bernard Shaw recogido en los Ensayos Fabianos bajo el significativo título de El malestar: «una señora neoyorkina que es por naturaleza de sensibilidad exquisita, encarga un sarcófago elegante de palisandro y plata, forrado de raso rosa, para su perro que murió. Éste se fabrica. Y mientras tanto un niño vivo ronda descalzo y hambriento por la cuneta al aire libre. El valor de cambio del sarcófago se considera como parte de la riqueza nacional. Pero a una nación que no puede permitirse alimentos y vestidos para sus niños, no se le puede consentir pasar por rica por haber proporcionado un sarcófago bonito para un perro muerto» ${ }^{1}$.

${ }^{1}$ Ensayos Fabianos, Escritos sobre el socialismo, Ed. de M. M. Gutiérrez y F. Jiménez, Ministerio de Trabajo, Madrid, 1985, pág. 50. 
Así pues, y aunque la idea puede expresarse en términos más complejos y alambicados, resulta obvio que el volumen de riqueza social no es equivalente al volumen de bienestar social. Los grandes imperios de la antigüedad que, en la realidad o en la leyenda, dieron vida a joyas incomparables, pudieron gozar de gran riqueza, pero nadie les calificaría como ejemplos de bienestar; como tampoco parecen ser ejemplos de bienestar aquellos países que atesoran enormes recursos mineros o naturales, pero que permiten la miseria entre amplias capas de población. En suma, desde un punto de vista colectivo, no creo que riqueza y bienestar sean términos equivalentes.

En realidad, me parece que el de bienestar no es un concepto cuantitativo, que se pueda medir en unidades homogéneas ${ }^{2}$ que admita comparaciones significativas con otras situaciones globales de bienestar/malestar, sino que se muestra más bien como un concepto relativo que hace alusión al reparto de la riqueza social, con todo lo dudoso que pueda resultar determinar los elementos que componen esa riqueza. En otros términos, parece seguro que sin alguna riqueza no cabe esperar que alumbre ningún bienestar, pero el grado de bienestar no es una función de la riqueza, sino de su reparto.

Pero esta relativización no supone abrazar una idea puramente subjetivista de bienestar. A. Sen y, entre nosotros, M. Valdés y J. Malem ofrecen una aproximación correcta a este problema conceptual ${ }^{3} \mathrm{~S}$ : una persona puede sentirse bien porque no conoce nada mejor, porque ha escogido la vida de penitencia, porque se siente satisfecha cumpliendo el destino marcado por algún logos universal o por cualquier otra circunstancia. Desde luego, nada se opone a concebir el bienestar en estos términos, pero de aquí pocas enseñanzas podemos derivar $\mathrm{y}$, sobre todo, pocas exigencias de comportamiento cabe dirigir a la comunidad política. De un lado, porque los ideales de excelencia o de felicidad son extremadamente plurales y difícilmente compatibles en una política de bienestar y, de otro, porque acaso resulta imposible promover la felicidad individual sin incurrir en alguna forma

${ }^{2}$ Creo que la ponencia de Martín D. Farrell ofrece esta imagen del nivel de vida cuando se concibe en función de la opulencia y del tiempo libre. Ciertamente, él no identifica bienestar y nivel de vida, pero, en todo caso, ¿cómo diseñar una función social del nivel de vida a partir de los niveles de vida individuales?, ¿sumando opulencias? Su sugerencia de que el nivel de vida colectivo pueda cifrarse en la opulencia del grupo mayoritario me parece francamente discutible.

${ }^{3}$ A. Sen, The Standard of Living, Cambridge University Press, 1987, pág. 8 y sigs. 
rechazable de paternalismo o de confesionalidad más o menos encubierta ${ }^{4}$.

Esto no significa necesariamente que hayamos de compartir la posición de J. Griffin a propósito de esa tensión que él presenta entre deseos y valores: ante la pregunta -vieja reformulación de interrogantes teológicos- acerca de si deseamos algo porque es valioso o si algo es valioso porque lo deseamos me parece que Griffin se esfuerza algo inútilmente por mostrarnos una idea objetiva de valor basada en la recomendación kantiana de prescindir de lo particular, histórico y contingente. A mí modo de ver no es éste el problema; deseamos lo que deseamos $\mathrm{y}$, por fortuna, la rica pluralidad del género humano nos ofrece ejemplos para todos los gustos. Lo que ocurre es que -desde el punto de vista de la filosofía política o de la decisión colectiva- resulta bastante complicado diseñar una función de bienestar sobre la base de las preferencias individuales, en particular si aceptamos, como hemos de aceptar, que en principio todas ellas merecen igual consideración y respeto.

Así pues, el rechazo -por irrelevante- de una noción subjetiva de bienestar tampoco ha de conducirnos necesariamente a una definición de naturaleza objetiva apoyada en algún «supervalor» de orden universal o, como parece defender Griffin, en una jerarquización de valores prudenciales de mayor importancia que los deseos. Entiendo que, en una sociedad liberal, el bienestar no es un valor en sí mismo que comprenda ciertos estados materiales y espirituales que deban imponerse incluso contra las preferencias de los individuos, sino que aparece más bien como un instrumento cuya satisfacción es tan sólo un medio para que las personas alcancen sus deseos. Es decir, la definición de una función de bienestar no se basa en una contraposición de valores y deseos. Estos últimos no se discuten; simplemente, se les tiene en cuenta a la hora de determinar los elementos que han de componer el horizonte de bienestar por cuanto los mismos representan el modo de realizar las preferencias.

Por ello, creo también que el bienestar es un concepto histórico vinculado a las condiciones materiales de existencia y que bien puede servir para poner en relación dos elementos en tensión: lo que se tiene y lo que se necesita, entendiendo que quienes poseen y quienes precisan son los miembros de una comunidad humana dotada de autonomía para decidir la atribución de

${ }^{4}$ En cambio, no suscribiría la afirmación de Malem en el sentido de que una concepción subjetiva del bienestar daría entrada a la promoción de deseos inmorales, al menos si no se matiza con cuidado qué se entiende por inmoral... 
recursos a la satisfacción de determinados fines. Y no se diga que ello desemboca en el cínico resultado de considerar más feliz a la pobre mujer de una tribu africana, quien por no tener carece hasta de deseos, que a la ociosa dama norteamericana abrumada por la obesidad. Sin duda, es casi intuitivo decir que esta última goza de mayor bienestar, pero para que esta afirmación tenga sentido es preciso que las consideremos formando parte de una misma comunidad, y aquí conviene diferenciar el plano ético del político. En el primero, la comparación es posible -y deseable- por cuanto la comunidad se identifica con el género humano en un cierto momento de su historia ${ }^{5}$; en el plano político, en cambio, y en tanto el llamado Derecho Internacional sea un Derecho positivo, el horizonte de bienestar se limita al de la riqueza disponible y en función de las necesidades efectivas.

Por consiguiente, creo que el bienestar debe configurarse como un concepto relativo y gradual. Relativo porque la definición de una función de bienestar depende del desarrollo de las fuerzas productivas, de los descubrimientos científicos, del refinamiento cultural y, si se quiere, también de las circunstancias demográficas y climáticas. Y gradual, porque del bienestar no se goza o se carece a la manera de todo o nada, sino que se disfruta en una cierta medida o cantidad, de acuerdo con el reparto de los recursos disponibles y de las cargas que hayan de asumirse.

Esto último supone que la idea de bienestar o de malestar sólo adquiere sentido cuando se proyecta sobre objetos que la gente necesita, pero que al mismo tiempo la comunidad posee en una cierta cantidad, y que asimismo resultan susceptibles de reparto o distribución. En efecto, no me parece significativo definir una función de bienestar en relación con aquello que no se necesita, ya sea porque la necesidad no se ha hecho perceptible -v. gr. la televisión hace cien años-, ya sea porque la sociedad proporciona bienes ilimitados de ese género; como tampoco resulta significativo respecto de aquello que nadie puede tener porque la sociedad en cuestión no puede proporcionarlo.

Bien es cierto que esta relativización introduce un nuevo elemento de complejidad a la hora de determinar los elementos que han de ser ponderados en una función de bienestar; porque si ha de tratarse de objetos necesarios pero escasos, es evidente que la composición del bienestar variará según la comunidad que contemplemos y según la perspectiva, universal o «provinciana», que

${ }^{5}$ Con todo, es probable que, aun gozando de una información completa, por motivos culturales y hasta climáticos la mujer africana no siente ninguna necesidad de ciertos bienes occidentales. 
se adopte. Me explico: variará según la comunidad porque, por ejemplo, el disfrute del agua resultará esencial en una zona desértica y apenas apreciable en un vergel; y variará según la perspectiva que se adopte, porque cierto bien puede ser gozado igualitariamente dentro de una comunidad política, pero aparecer como francamente desigualitario cuando comparamos diferentes comunidades. Por ello, estoy de acuerdo con Martín D. Farrell cuando dice que la libertad o los bienes públicos -v. gr., la calidad del aire- no cuentan para definir el nivel de vida, y ello, entre otras razones, porque el máximo goce de esos bienes por una persona es compatible con igual goce por parte de las demás, pero estoy de acuerdo a condición de circunscribir ese nivel de vida a las fronteras de una comunidad nacional, donde efectivamente las libertades y los bienes públicos se atribuyen igualmente a todos los ciudadanos; no lo estaría tanto desde una perspectiva ética o universal, donde ese reparto resulta desigual ${ }^{6}$.

Por ello, entiendo que allí donde cabe hablar de igualdad jurídica o formal resulta superfluo preguntarse por el bienestar; la protección estatal de la vida o la libertad de expresión son -en principio- idénticas para el opulento y para el desheredado y, si podemos decir que su bienestar es diferente, ello obedece justamente a que no tomamos en cuenta esos elementos. El problema del bienestar, en consecuencia, aparece respecto de aquellas cosas que se necesitan, pero que el sistema puede proporcionar sólo limitadamente; si cabe un disfrute ilimitado por parte de todos los miembros de la comunidad, la cosa en cuestión deja de ser relevante en una función de bienestar? ${ }^{7}$ Por eso, pienso que hoy las libertades no forman parte del bienestar, pero que hubieron de constituir un elemento básico en el marco de una sociedad esclavista.

Dicho esto, creo que hemos avanzado algo en la definición del bienestar individual, que pudiéramos concebir como la participación de una persona en el disfrute de aquellos bienes escasos y necesarios que componen lo que solemos llamar riqueza social. Entonces, es obvio que el bienestar colectivo no puede estar formado por la suma de esas participaciones, pues, cualquiera

${ }^{6}$ Por lo demás, no puedo compartir la distinción que formula Martín D. Farrell entre nivel de vida y bienestar, así corno tampoco su rechazo de las ideas de necesidad e igualdad en orden a definir el nivel de vida colectivo. Él insiste mucho en el dato de la opulencia, pero ¿qué es la opulencia sino el grado de participación en los bienes escasos y necesarios?

${ }^{7}$ Como deja de ser relevante también desde la perspectiva de la justicia. Vid. A. Heller, Más allá de la justicia, Ed. Crítica, Barcelona, 1990, págs. 232 y sigs. 
que fuera el reparto, el resultado sería siempre el mismo. Por el contrario, si queremos evitar la identificación entre bienestar colectivo y riqueza social, entiendo que aquél debe hacerse depender de la máxima optimización de los «bienestares» individuales según un criterio de igualdad; es decir, dado que no tiene sentido sumar las participaciones, lo que procede es sumar los niveles de satisfacción y éstos dependen de la relación entre el número de unidades a repartir y el número de sujetos a intervenir en el reparto. En hipótesis, el más alto grado de bienestar colectivo se dará cuando cada individuo alcanza el más alto grado de bienestar individual compatible con idéntico bienestar de los demás.

Me parece que Martín D. Farrell no estaría muy conforme con esta idea cuando dice que «llegaríamos a la extraña conclusión de que sólo las sociedades absolutamente igualitarias tienen un nivel de vida alto, cualesquiera que sea su nivel de ingreso». De nuevo, el problema reside en fijar los términos de la comparación: yo sí creo que una sociedad pobre pero igualitaria disfruta en su seno de un bienestar colectivo superior al de una sociedad rica pero injusta. Otra cosa es que la opulencia o el volumen de riqueza de esta última sea más alto, y otra cosa es que, comparando globalmente ambas sociedades, también sea más alto el bienestar de la sociedad rica, que goza de una mayor participación en el disfrute de unos bienes que, moralmente, acaso pertenecen al conjunto de la humanidad.

En este sentido, hablar de un bienestar igualitario ${ }^{8}$ no diré que resulta tautológico, pero sí que el adjetivo tan sólo viene a explicar mejor algo que está ínsito en la idea de bienestar, al menos si no queremos identificarla con la de riqueza social. Lo cual, por cierto, pone de relieve que el bienestar constituye un concepto clave de la justicia y del Derecho, aunque sólo sea porque, de Hume a Marx, la escasez y su reparto se han considerado la misma razón de ser del orden jurídico y, al propio tiempo, una de las preguntas fundamentales que ha de contestar toda doctrina de la justicia.

Ahora bien, que rechacemos la identificación entre riqueza y bienestar, tampoco significa que aquélla sea irrelevante y que no resulte afectada por el modelo de reparto. Es obvio que a mayor opulencia colectiva mayores podrán ser las cuotas de participación individual y es muy probable también que la creación de riqueza social esté muy condicionada por el modo de entender la

${ }^{8}$ D. Lyons, por ejemplo, distingue entre un bienestar utilitario y un bienestar igualitario, Ética y Derecho, trad. de M. Serra, Ariel, Barcelona, 1986, págs. 121 y sigs. 
igualdad. Este es un problema -el de la eficacia global del sistema para crear riqueza- en el que no podemos detenernos, pero que nos llevaría a preguntarnos acerca de qué tipo de igualdad es compatible con el mayor incremento de la riqueza social ${ }^{9}$. Como es sabido, muchos han pensado que el igualitarismo constituye el umbral de la pobreza, pero no es ésta nuestra perspectiva; en cualquier caso, la cantidad total de bienes que posee una sociedad puede ser la premisa fáctica del bienestar -elemento no despreciable, desde luego-, pero insisto en que, a mi juicio, el grado de bienestar social es un problema de reparto.

Así pues, parece que el concepto de bienestar social gira en torno a la idea de reparto igualitario en el disfrute de la riqueza y en la asunción de las cargas sociales. En este aspecto coincido con Barragán cuando dice que una función de bienestar colectivo tiende a producir la distribución de un bien escaso o de una determinada carga social, así como que, consecuentemente, ello implica trazar límites a las preferencias e intereses expresados en las funciones individuales. De entrada, ello supone mostrar un mayor optimismo que aquellos que piensan que nombrar el bienestar colectivo es poco menos que mentar la esclavitud individual; pero también más pesimismo que aquellos otros que confían obtener ese bienestar mediante el malabarismo de alguna mano invisible, es decir, como una adición de utilidades individuales. En suma, plantearse el bienestar colectivo como un problema moral y político supone partir de la hipótesis de que éste no nace espontáneamente del libre juego de los sujetos y fuerzas sociales -pues, si así fuera, no existiría propiamente ningún problema-, pero también de que constituye un objetivo alcanzable y justificable a pesar de las restricciones que pueda suponer para ese libre juego.

Estimo que, desde esta perspectiva, el bienestar da lugar a tres clases de problemas, que aquí apenas pueden quedar enunciados: primero, qué justificación moral puede alegar una decisión pública acerca del reparto de cargas y recursos; segundo, qué tipo de cosas o de necesidades pueden ser objeto de una política de bienestar; y tercero, quién ostenta legitimidad para decidir cómo se construye y a qué precio un bienestar colectivo.

La respuesta a la primera pregunta aparece lógicamente conectada

${ }^{9}$ Aunque no conteste directamente a esta cuestión, son interesantes las consideraciones de A, Sen, «igualdad de qué?», en J. Rawls y otros, Libertad, Igualdad y Derecho, S. M. McMurrin (ed.), trad. de G. Valverde, Ariel, Barcelona, 1988, págs. 131 y sigs. 
al modelo de justicia que se postule. Si se parte de la concepción liberal de que la salud pública no consiste en procurar la salvación del alma, ni la virtud, ni el disfrute de cosas materiales, sino en salvaguardar la libertad de todos para que cada cual persiga sus fines religiosos, éticos o económicos ${ }^{10}$, -esto es, su bienestar entendido como felicidad subjetiva o como satisfacción de deseos o preferencias- parece cierto que una política de bienestar o de interferencia en el juego de las utilidades individuales difícilmente puede hallar alguna justificación; es más, quienes se muestran más fieles a sus orígenes parecen ver en cualquier política de bienestar una amenaza para las libertades y un riesgo cierto de desembocar en fórmulas de cuasi esclavitud; no es preciso recordar el caso de Nozick.

Por mi parte, creo que es posible mantener esas premisas liberales y antipaternalistas sin tener que compartir necesariamente sus consecuencias. Aquella libertad kantiana, formal y negativa, constituía tal vez el máximo horizonte de justicia que podía ofrecer una razón monológica, que hacía expresa renuncia de lo particular e histórico, es decir, de las necesidades; y de ahí que esa razón suministrase una filosofía política negativa que nos enseñó lo que no se debe hacer y, consecuentemente, que detuvo la acción del Estado en la simple represión de las acciones dañinas para las demás personas ${ }^{11}$. Pero sospecho que el propio Kant nos ofreció alguna «pista» de por dónde podían ir las cosas cuando a su ciudadano activo que ejerce la libertad positiva le exige la condición de independencia, esto es, la condición empírica de no deber la existencia más que a sus propias fuerzas o, si se quiere, de gozar del ocio necesario para pensar.

No insistiré en las razones que avalan una concepción integral de los derechos ${ }^{12}$, pero si Kant admitía que el ejercicio de la libertad, al menos de la libertad participación, requiere cierto nivel de vida, ello puede permitirnos configurar el bienestar colectivo como un valor instrumental al servicio de esa libertad, especialmente desde el momento en que ésta se presenta como una exigencia universal a la que todos tienen derecho. El liberalismo del sufragio censitario hizo del bienestar individual un presupuesto de la libertad política que se desarrolla una vez concluido

${ }^{10}$ Vid. I. Kant, La metafísica de las costumbres, trad. de A. Cortina y J. Conill, Tecnos, Madrid, 1984, pág. 147.

${ }^{11}$ Vid. J. Stuart Mill, Sobre la libertad (1859), trad. de J. Sainz, Orbis, Barcelona, 1985, págs. 32 y sigs.

${ }^{12}$ Vid. mis Estudios sobre derechos fundamentales, Debate, Madrid, 1990, págs. 43 y sigs. 
el monólogo moral fundamento de la libertad negativa. La filosofía del sufragio universal, estimulada por la conciencia igualitaria, hizo tabla rasa de aquella condición del bienestar, acaso sin caer en la cuenta de que la misma no era sólo una disculpa para excluir a los trabajadores y a las mujeres del proceso político, sino un requisito indispensable para el efectivo disfrute de los derechos. Por eso, creo que justificar hoy la legitimidad de una política de bienestar, o sea, de reparto, supone recuperar una vieja idea del liberalismo estrechamente vinculada a la teoría de los derechos; en suma, si un cierto nivel de vida constituye un presupuesto para el ejercicio de la libertad y ésta ha dejado de ser un privilegio para postularse como un bien universal al que todos deben tener derecho, entonces ese nivel de vida puede integrarse como un elemento más de aquello a lo que todos deben tener derecho.

En otras palabras, desde esta perspectiva una política de bienestar consistente en la distribución de los recursos encontraría su justificación en la propia doctrina de los derechos; es el derecho a gozar de las libertades lo que estimula una decisión pública en favor de la consecución de un nivel de vida para todos los titulares de esas libertades que permita transformar su titularidad formal en ejercicio real. Política de bienestar que, a mi juicio, no debe verse como la encarnación de alguna regla de utilidad en permanente polémica con las libertades, sino como un modo de satisfacer también auténticos derechos. Por ello, creo que tras los derechos sociales es posible encontrar algo más serio que retórica electoral; es posible encontrar exigencias que deben ser satisfechas aun cuando con ello no se maximice la utilidad general entendida como simple incremento de la riqueza, y de ahí que haya rehusado ver en el bienestar colectivo un reflejo del volumen de riqueza y sí, en cambio, de su reparto.

La segunda cuestión que había quedado pendiente se refería a las cosas que pueden ser objeto de una política de bienestar. No creo que admita una respuesta categórica, pues depende de la relación existente entre las necesidades sentidas por un cierto grupo humano y la riqueza o los bienes de que disponga para su satisfacción. Ahora bien, ¿qué tipo de necesidades son relevantes y qué clase de sacrificios pueden pedirse en nombre del bienestar? Martín D. Farrell no es partidario de dar prioridad a la idea de necesidades y a tal fin nos propone el siguiente ejemplo: «imaginemos una sociedad de tres individuos, $x, y$, y $z$. El individuo $\mathrm{x}$ necesita actividad sexual, pero $y$ y $z$ prefieren no tener relaciones sexuales con $x$. Si las necesidades priman siempre frente a las preferencias habría que obligar a $y$ y $z$ a satisfacer la 
necesidad de $x$, dejando de lado su preferencia en contrario». Permítaseme variar ligeramente los términos: $x$ prefiere mantener relaciones con $y$, y no con $z$; y no necesita mantener relaciones sexuales o incluso necesita no mantenerlas, por ejemplo por motivos de salud. $\mathrm{Si}$ las preferencias priman sobre las necesidades, entonces y viene obligado a mantener relaciones sexuales $\operatorname{con} x$.

En realidad, creo que la cuestión está mal planteada: no es que las necesidades primen siempre sobre las preferencias o que éstas deban recibir en ocasiones una atención preferente, sino que, a la hora de repartir, ni valen todas las necesidades ni valen todas las preferencias. Seguramente, delimitar cuáles sí y cuáles no constituye un problema abierto al desarrollo cultural de cada sociedad y, en general, a sus condiciones materiales de existencia. No obstante, y aunque procuro huir de una solución concluyente, estimo que una política de bienestar sólo puede tener por objeto aquellas cosas que son susceptibles de un valor de cambio y que se inscriben en el capítulo de lo económico, social y cultural; dicho de otro modo, aquellas cosas sometidas a la competencia de la decisión colectiva y no aquellas otras que forman parte del ideal de una vida buena. Por eso, sospecho que los límites de una política de bienestar o de cualquier política a secas se hallarían en eso que se ha llamado una ética de mínimos; «ni la felicidad o las preferencias, ni las valoraciones o el sentido de la vida encuentran respuestas en la ética discursiva; de eso ya hablarán los afectados por las normas» ${ }^{13}$.

En particular, pienso que las técnicas propias del bienestar presentan poda virtualidad o resultan abiertamente nocivas cuando intentan proyectarse sobre las libertades o sobre la elección de preferencias; y no sólo porque, como he indicado, constituyen objetos poco susceptibles de reparto, sino especialmente porque ello puede conducir a una especie de neoconfesionalismo, laico o religioso, donde el Estado prime o fomente determinados ejercicios de la libertad, orientando las opciones éticas de sus ciudadanos. Según creo, algo de esto sucede ya entre nosotros ${ }^{14}$.

Por ello, me parece más fructífero conectar la idea de bienestar con la de satisfacción de necesidades; si fuera posible, asumiendo esa utopía racional de «el reconocimiento de todas las

${ }^{13}$ M. Gascón, Obediencia al Derecho y objeción de conciencia, C. E. C., Madrid, 1990, pág. 196.

${ }^{14}$ Vid, mi trabajo «Los derechos fundamentales tras diez años de vida constitucional», Sistema, 96, 1990, págs. 24 y sig. 
necesidades como idea constitutiva y el principio de satisfacción de todas las necesidades como idea regulativa», siempre que esto "excluya la utilización de los demás como meros medios» ${ }^{15}$. Cuando menos, postulando la satisfacción de aquellas necesidades cuya atención se requiere para alcanzar la «igualdad de la capacidad básica» ${ }^{16}$. Sea como fuere, necesidades e igualdad son nociones que siguen estando presentes, incluso en el lenguaje vulgar, a la hora de definir una política de bienestar.

Finalmente, la tercera pregunta que había quedado enunciada será la que respondamos con mayor brevedad, y no porque sea sencilla, sino porque abre un capítulo autónomo de la reflexión filosófico política. Quién ostenta legitimidad para diseñar una política de bienestar, al igual que quién la ostenta para decidir sobre los asuntos comunes, sólo puede tener hoy una respuesta: el conjunto de los ciudadanos. Nadie puede ser excluido del debate acerca de las necesidades atendibles y del correspondiente reparto de los recursos y de las cargas sociales. Como es sabido, la democracia representativa pasa por ser el sucedáneo del discurso moral.

No insistiremos en el creciente abismo que separa la práctica cotidiana de las instituciones democráticas respecto de los modelos teóricos que, desde Rousseau a Habermas, han querido servir como justificación e impulso de esa práctica; creo que a nadie se le escapa que las decisiones públicas no suelen ser el fruto de un diálogo abierto y simétrico realizado por sujetos situados en algo parecido a lo que pudiera ser la posición ideal de diálogo; lamentablemente, a veces parecen ser todo lo contrario. Sin embargo, si este diagnóstico es más o menos acertado en general, creo que resulta particularmente destacable en el ámbito de la política de bienestar, que suele ser el ámbito de lo económico y social.

En efecto, diríase que aquí la decisión democrática -léase parlamentaria- sufre un doble proceso de postergación o arrinconamiento. Postergación, en primer lugar, por parte de esa técnica sin ideas encarnada por los sacerdotes de la burocracia estatal, poseedores únicos de los nuevos arcanos de la dominación política, en el fondo no tan alejados de los que describiera Maquiavelo; son ellos los que parten y reparten pretendiendo además que su decisión no sea debatida porque, al parecer, es la única posible. A veces, da la impresión que los economistas actúan

${ }^{15}$ M. J. Añón Roig, «El sentido de las necesidades en la obra de Agnes Heller», Sistema, 96, 1990, págs. 132-134.

${ }^{16}$ Vid. A. Sen, «¿Igualdad de qué?», citado, págs. 151 y sigs. 
hoy con la misma ingenuidad -y arrogancia- que los juristas del siglo pasado, firmes creyentes en la plenitud lógica del ordenamiento y en el carácter mecánico y neutral de la jurisprudencia.

Traduciéndolo a términos jurídicos, tal vez esto explicaría las debilidades que presenta el principio de legalidad en todo lo relativo al bienestar y a los derechos sociales $\mathrm{y}$, consecuentemente, el relevante papel que todavía desempeña la potestad reglamentaria y la actuación administrativa. Sin embargo, no explicaría un segundo proceso de postergación de la decisión democrática, en apariencia menos reprochable o peligroso; me refiero a la proliferación de sectores o grupos autónomos de negociación y reparto que -bajo el lema de sálvese quien pueda- presionan y acuerdan políticas de bienestar privilegiadas, muchas veces en detrimento del conjunto de la población y, en ocasiones también, con una fuerte tendencia a la privatización de los servicios sociales. Y si bien es cierto que estas políticas sectoriales de bienestar no carecen de un fundamento democrático o consensual, expresado en acuerdos o convenios, no es menos cierto que lesionan el principio de igualdad que, como sabemos, constituye la idea regulativa del bienestar; es decir, suponen aprovechar una posición de ventaja, excluyendo del debate y de la decisión a quienes no participan en ella.

A modo de conclusión. Tras los instructivos trabajos que preceden a estas Notas, en los que he encontrado más motivos de acuerdo que de disputa, aquí tan sólo he querido mostrar que el de bienestar no es un concepto meramente descriptivo cuya modulación pueda quedar en manos de los sabios de la ciencia económica; puede y debe tener una dimensión social y política, si se quiere una dimensión resueltamente ideológica y valorativa, que ha de reposar en un análisis sereno y riguroso, pero que no se agota en él. Aun cuando en algún momento pudiera parecerlo, mi propósito no ha sido negar la relación entre riqueza y bienestar -de la que estoy persuadido-, sino negar su identificación; una identificación que sospecho que se halla implícita en algunas aproximaciones a este género de problemas. Desconozco los secretos que permiten incrementar la opulencia -y la dedicación a la Universidad es la mejor prueba de ello-, con lo cual desconozco también los secretos que en parte hacen posible un mayor bienestar; pero sólo en parte. En la otra parte, que a mi juicio es la más significativa, el bienestar social no es una función del volumen de riqueza, sino un exponente del modelo de justicia; de ahí la ponderación de ideas tales como necesidad e igualdad. 
Soy consciente de que en este trabajo tales ideas han sido tan sólo esbozadas y que no se ha hecho frente a los numerosos problemas que aparecen implicados; por ejemplo, ¿qué clase de igualdad reclama un objetivo de bienestar social?, ¿qué tipo de necesidades pueden ser atendidas y en qué orden?, ¿cómo influye todo ello en el incremento de la riqueza colectiva?, etc. Por el momento, únicamente he querido plantear una idea bastante modesta, y es que la medida del bienestar colectivo no puede prescindir de lo que los individuos necesitan y de cómo se distribuyen los recursos para su satisfacción. Asimismo, he procurado aportar algunas razones en favor de los decisiones públicas que, interfiriendo en el entramado de las relaciones privadas, pretenden hacer efectivo un modelo de bienestar social. 